\title{
Sistem Informasi Geografis Untuk Pelaporan Dan Pelacakan Kejahatan Berbasis Android Pada Polres Gorontalo Kota
}

\author{
Marlin Lasena ${ }^{1}$, Sulistiawati Rahayu Ningsi Ahmad ${ }^{2}$ \\ ${ }^{1}$ e-mail: marlinlasena@gmail.com, ${ }^{2}$,sulistiawatiahmad@gmail.com, \\ ${ }^{1}$ Sistem informasi, STMIK Ichsan Gorontalo, \\ ${ }^{2}$ Teknik Elektro, Universitas Ichsan Gorontalo.
}

\begin{abstract}
Geographic Information Systems (GIS) is a computer-based information system for storing, managing and analyzing, and calling geographicly differential data that has grown rapidly in the last five years. This rapid technological advance has led more and more people to benefit, one of which is to provide information on crime reporting and tracking in the city's gorontalo police. This research is focused on the city's gorontalo police related to reporting and tracking information especially related to crime location information. From the results of the study found that there is still very little use of technology to present information to the police in Gorontalo city, this is certainly a condition that irony in the midst of the rapid state of technology development today. Research System is implemented and can make it easier to provide information navigation point location reporting and tracking crimes that occur in gorontalo police area of the city and have been through system testing (Blackbox and Whitebox).
\end{abstract}

\section{Keywords - Geographic information systems, Android, tracking reporting}

Intisari - Sistem Informasi Geografis (SIG) merupakan suatu sistem informasi berbasiskan komputer untuk menyimpan, mengelolah dan menganalisis, serta memanggil data bereferensi geografis yang berkembang pesat pada lima tahun terakhir ini. Kemajuan teknologi yang pesat ini membuat semakin banyak orang yang mendapatkan manfaat salah satunya adalah untuk memberikan informasi pelaporan dan pelacakan kejahatan pada polres gorontalo kota. Penelitian ini difokuskan pada polres gorontalo kota berkaitan dengan informasi pelaporan dan pelacakan khususnya terkait dengan informasi lokasi kejahatan. Dari hasil penelitian ditemukan bahwa masih sangat minimnya pemanfaatan teknologi untuk menyajikan informasi kepada polres gorontalo kota, hal ini tentu merupakan kondisi yang ironi ditengah keadaan pesatnya pekermbangan teknologi saat ini. Penelitian Sistem ini diterapkan dan dapat mempermudah untuk memberikan informasi navigasi titik lokasi pelaporan dan pelacakan kejahatan yang terjadi di wilayah polres Gorontalo kota dan telah melalui pengujian sistem (Blackbox dan Whitebox)

Kata Kunci-Sistem informasi Geografis, Android, pelaporan pelacakan

\section{PENDAHULUAN}

Sistem Informasi Geografis (SIG) merupakan suatu sistem informasi berbasiskan komputer untuk menyimpan, mengelolah dan menganalisis, serta memanggil data bereferensi geografis yang berkembang pesat pada lima tahun terakhir ini. Manfaat dari SIG adalah memberikan kemudahan pada para pengguna atau para pengambil keputusan untuk menentukan kebijaksanaan yang akan diambil. Kemajuan teknologi yang pesat ini membuat semakin banyak orang yang mendapatkan manfaat salah satunya adalah untuk memberikan informasi pelaporan dan pelacakan kejahatan pada polres gorontalo kota.

Penelitian ini difokuskan pada polres gorontalo kota berkaitan dengan informasi pelaporan dan pelacakan khususnya terkait dengan informasi lokasi kejahatan. dari hasil penelitian ditemukan bahwa masih sangat minimnya pemanfaatan teknologi untuk menyajikan informasi kepada polres gorontalo kota, hal ini tentu merupakan kondisi yang ironi ditengah keadaan pesatnya pekermbangan teknologi saat ini. lokasi kejahatan dapat dilakukan menggunakan fasilitas google maps yang tersedia, namun menggunakan fasilitas ini tentu tidak dapat memberikan informasi secara detail tentang lokasi kejahatan tersebut. Selain itu masi terdapat beberapa lokasi kejahatan yang belum terdaftar pada lokasi lain dan juga masih banyak tindak kejahatan yang belum dapat ditangani dengan cepat dikarenakan proses pelaporan masyarakat masih sangat lambat.

Hasil dari penelitian dilokasi mendapatkan data hasil dari laporan masyarakat dari tahun 2017, 2018, 2019, dan 2020. Tahun 2017 memiliki laporan masuk sejumlah 1.142 laporan. Tahun 2018 memiliki laporan masuk sejumlah 1.181 laporan. Tahun 2019 memiliki laporan masuk sejumlah 941 laporan. Tahun 2020 memiliki laporan masuk sejumlah 80 laporan, jenis laporan di 
bulan januari ada berbagai jenis yaitu Pencurian, perkelahian, penyakit masyarakat panah wayar, perjudian dan miras. Jadi totalnya semua untuk 4 tahun memiliki total laporan sejumlah 3.344 laporan. Saya tidak bisa menerangkan laporan keseluruhan untuk tiap tahunnya tentang apa saja yang telah dilaporkan oleh masyarakat setempat dikarenakan laporan tersebut menurut pihak Reserse Kasat Reskrim sangat mengandung data rahasia. Tetapi saya mencoba untuk meminta laporan di yang paling sedikit di bulan januari apa saja yang telah dilaporkan oleh masyarakat dan akhirnya diberikan oleh pihak Reserse Reskrim.

\section{TUJUAN PENELITIAN}

Tujuan dalam penelitian ini adalah

1. Merancang sistem informasi geografis berbasis android untuk memberikan informasi navigasi titik lokasi pelaporan dan pelacakan kejahatan yang terjadi di wilayah polres Gorontalo kota.

2. Meminimalisirkan tingkat kejahatan yang mungkin lambat ditangani dikarenakan lambatnya masyarakat memberikan informasi kejahatan.

\section{METODE PENELITIAN}

\section{Gambaran Umum Lokasi Penelitian}

Kantor Polres Gorontalo kota merupakan instansi yang berperan aktif dalam administrasi pemerintahan, pembangunan dan pemasyarakatan yang khususnya melayani, melindungi dan mengayomi masyarakat. Kantor Polres Gorontalo kota terdiri atas beberapa bagian, satuan fungsi dan seksi yaitu : Bag Ops, Bag Ren, Bag Sumda, Sat Intelkam, Sat Reskrim, Sat Sabhara, Sat Lantas, Sat Binmas, Sat Tahti, dan bagian lain seperti Sium, Sikeu, Sipropam, Sitipol, serta 7 Polsek sebagai ujung tombak pelaksanaan tugas sehari-hari.

\section{Objek Penelitian}

Berdasarkan latar belakang dan kerangka pemikiran yang telah diuraikan pada bab sebelumnya, maka yang menjadi objek penelitian ini adalah Penerapan Sistem Inromasi Geografis untuk Pelaporan dan Pelacakan Kejahatan Pada Pada Polres Gorontalo kota Berbasis Android.

\section{Metode Penelitian}

Metode penelitian yang digunakan dalam penelitian ini adalah metode deskriptif, yaitu metode penelitian yang berusaha untuk memecahkan masalah yang ada sekarang secara sistematis berdasarkan data-data yang diproleh.Metode deskriptif ini bertujuan untuk gambaran secara sistematis, aktual, terinci, dan akurat mengenai fakta-fakta, sifat-sifat serta hubungan antar yang diteliti.

\section{Tahap Analisis}

Langkah ini merupakan analisis tahap pengumpulan data, dalam tahap ini bisa melakukan tahap penelitian. Wawancara atau studi kasus literature, sistem analisis akan menggali informasi sebanyak-banyaknya dari user sehingga akan menghasilkan sebuah dokumen user requetmant atau bisa dikatakan sebagai data yang berhubungan dengan jaringan user dalam pembuatan sistem. Dokument ini akan menjadi acuan sistem analisis untuk menerjemahkan kedalam bahasa pemograman.

\section{Identifikasi Masalah}

Penyebab Permasalahan, seperti yang telah dibahas di atas yaitu sering terjadi ketidak jelasan lokasi, ataupun alamat kejadian kejahatan yang diterima oleh pihak kepolisian dari masyarakat, sehingga mengakibatkan proses penanganan sangat lambat

\section{ANALISIS DAN DESAIN SISTEM}

\section{Analisa Sistem yang diusulkan}

Sistem yang diusulkan digambarkan dengan usecase diagram di bawah ini. 




Gambar 4.1 Sistem yang diusulkan

Polres Gorontalo kota menindak lanjuti hasil laporan masih tetap sama dengan sistem yang berjalan. Akan tetapi pada sistem yang diusulkan permasalahan yang ditemui pada sistem yang sedang berjalan khususnya untuk mempermudah dalam pelaporan tanpa harus datang ke kantor polres Gorontalo kota. Pemberitahuan lebih lanjut terhadap pelaporan yang telah dilakukan juga dapat dilakukan melalui sistem aplikasi yang akan dibuat dan dilengkapi dengan system pelacakan yg memanfaatkan SIG (Sistem Informasi Geografis) agar dapat lebih mudah dan cepat menangani kejahatan yang sedang terjadi.

\section{Tampilan Aplikasi}

Tampilan sistem pada server rancang sangat sederhana, sedangkan tampilan sistem yang berjalan di client dirancangan dengan mengoptimalkan kemudahan pengguna. Berikut merupakan tampilan Graphic User Interface dari sistem yang diusulkan :

\section{Halaman Login Admin}

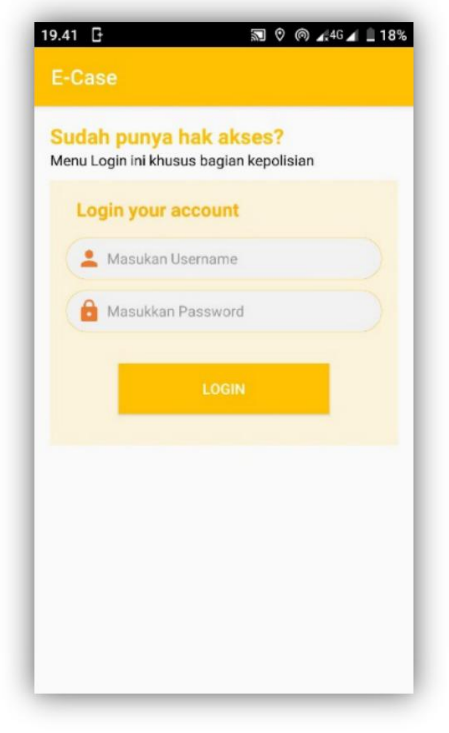

Gambar 4.2 login

Halaman di atas digunakan untuk login ke halaman Adminsitrator. Administrator disini adalah bagian admin Reskrim Pada Polres Gorontalo kota 
Halaman Data Laporan



Gambar 4.3 Halaman data laporan

Halaman ini menampilkan data laporan. Data laporan ini merupakan hasil data laporan yang diinputkan oleh masyarakat sendiri secara langsung dari aplikasi E-Case di android.

Halaman Input Data Laporan

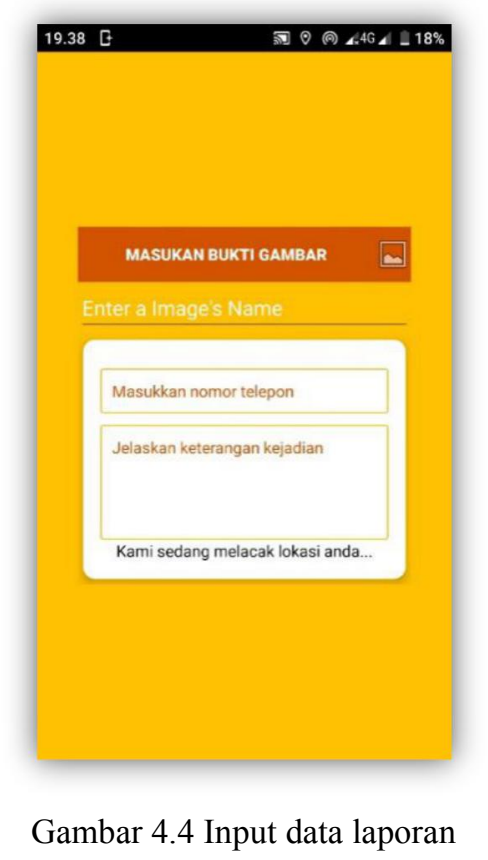

Halaman di atas digunakan untuk menginputkan data laporan baru yang akan digunakan oleh masyarakat untuk membuat laporan baru tentang kejadian kejahatan yang sedang terjadi ataupun sudah terjadi.

\section{Implementasi Sistem}

Sistem yang dirancang selanjutnya akan diimplementasikan pada Polres Gorontalo Kota. Untuk aplikasi mobile sisi administrator akan langsung di pasang pada handphone bagian reserse reskrim pada polres Gorontalo kota. dan akan dioperasikan oleh seluruh staf polisi bagian reserse reskrim, selanjutnya aplikasi ini juga akan bisa digunakan untuk masyarakat 
sebagai user dan tidak membutuhkan login khusus agar masyarakat dapat dengan mudah melaporkan sesuatu kejadian kejahatan yang sedang terjadi ataupun sudah terjadi. Untuk menjalankan aplikasi ini dibutuhkan smartphone dengan sistem operasi android minimum adalah Ice Cream Sandwich (ICS). Aplikasi ini juga membutuhkan internet untuk dapat mengoperasikan aplikasi dan mengirimkan laporan kejahatan.

\section{KESIMPULAN}

Penelitian Sistem ini diterapkan dan dapat mempermudah untuk memberikan informasi navigasi titik lokasi pelaporan dan pelacakan kejahatan yang terjadi di wilayah polres Gorontalo kota dan telah melalui pengujian sistem (Blackbox dan Whitebox)

\section{SARAN}

Saran untuk pengembangan penelitian ini adalah sebagai berikut:

1. Untuk pengembangan aplikasi nanti sebaiknya menambahkan fitur-fitur yang lain. Karena akan lebih menghasilkan kontribusi penelitian yang dapat membedakan dengan penelitian ini.

2. Penerapan material untuk sistem operasi android terbaru, misalnya untuk pie dan Andorid ten untuk membuat tampilan program lebih semakin menarik.

\section{REFERENSI}

[1] N. Safaat, Android Pemograman Aplikasi Mobile Smartphone dan Tablet PC Berbasis Android, Bandung: erlangga, 2012.

[2] K. M. Wibowo, I. Kenedi and J. Jumadi, "Sistem Informasi Geografis Menentukan Lokasi Pertambangan Batu Bara di Provinsi Bengkulu Berbasis Web," Jurnal Media Infotama, vol. XI, no. 1858-2680, p. 51, 2015.

[3] M. Arif, Z. Arham and I. Aminudin, "Racangan Bagun Sistem Informasi Geografis Kesesuaian Lahan Tanaman Jagung Berbasis WEB," Jurnal Agribisnis, vol. IX, no. 1979-0058, pp. 49-60, 2015.

[4] N. A. Safrudi, "Sistem Informasi Geografis Perkebunan PT Cengkeh Zanzibar Kebun Kalisidi," Semarang, 2017.

[5] A. Arifianto, "Penerapan Sistem Informasi Geografis Dalam Pemetaan Produksi Pertanian Di Kabupaten Bone," Aziz Arifianto, Yogyakarta, 2015.

[6] Esri, Understanding GIS : The Arc/ Info Method Environmental System, California: Research Institute, Redlands, 1990.

[7] Y. Yousman, Sistem Informai Geografis denga Mapinfo Profesional, Yogyakarta: Penerbit Andi, 2004.

[8] Turban and R. Kono, "Skripsi Sistem Informasi Geografis Letak Lokasi Service Handphone Berbasis Android," Ruslan Kono, Gorontalo, 2017.

[9] N. Safaat, Pemrograman Aplikasi Mobile Smarphone dan Table PC Bebasis Android, Bandung: Informatika, 2012.

[10] Y. Supriadi, Semua Bisa Menjadi Programmer Android, Jakarta: PT Elex Media Komputindo, 2014.

[11] F. Ableson, R. Sen and C. , Android in Action, Second Edition, Stamford: Manning Publications Co, 2011.

[12] K. Abdul, Belajar Sendiri Pasti Bisa Pemrograman PHP, Yogyakarta: Andi, 2015.

[13] A. Hartono, Rekayasa Sistem Berorientasi, Bandung: Informatika, 2009.

[14] K. Abdula, Tuntunan Praktis Belajar Database Menggunakan MySQL, Yogyakarta: C.V Andi Offset, 2008.

[15] S. Dharwiyanti, "Pengantar Unified Modeling Language (UML)," 2003.

[16] A. Dennisq, B. H. Wixom and D. Tegarden, Systems Analysis and Design with UML Version 2.0, United States of America: Leyh Publishing, 2005.

[17] A. B. B. Ladjamudin, Rekayasa Perangkat Lunak, Yogyakarta: Graha Ilmu, 2006.

[18] Sugiono, Metode Penelitian Kualitatif, Kuantitatif, dan R\&D, Bandung: Alfabeta, 2011.

[19] Sudaryono, S. Guritno and U. Rahardja, Theory and Application of IT Research, Yogyakarta: Andi Offset, 2011. 